\title{
Critical Comparison of Reference Electrodes with Salt Bridges Contained in Nanoporous Glass with 5, 20, 50, and $100 \mathrm{~nm}$ Diameter Pores
}

\author{
Evan L. Anderson, Blair K. Troudt, and Philippe Bühlmann ${ }^{\dagger}$ \\ Department of Chemistry, University of Minnesota, 207 Pleasant St. SE, Minneapolis, MN 55455, USA
}

\begin{abstract}
Porous glass frits are frequently used to contain the salt bridges through which reference electrodes interface samples. Prior work with widely used glass frits with $4-10 \mathrm{~nm}$ diameter pores showed that, when samples have a low electrolyte strength, electrostatic screening of sample ions by charged sites on the glass surface occurs. This creates an ion-specific phase-boundary potential at the interface between the sample and frit, and it biases the potential of the reference half-cell. Use of frits with much larger pores eliminates this problem but results in the need for frequent replenishing of the bridge electrolyte. A methodical study to determine the optimum pore size has been missing. We show here that charge screening of sample ions occurs when the pore size of nanoporous glass frits is on the order of $1-50 \mathrm{~nm}$ and samples have a low electrolyte strength. An increase in pores size to $100 \mathrm{~nm}$ eliminates charge screening in samples with ionic strengths in the $1.0 \mathrm{M}$ to $3.3 \times 10^{-4} \mathrm{M}$ range. However, the rates of electrolyte solution flow through frits with $1,5,20$, 50, and $100 \mathrm{~nm}$ pores are still low, which makes diffusion the dominant mode of ion transport into and out of these frits. Consequently, the flow of bridge electrolyte into samples is not fast enough to prevent diffusion of ions and electrically neutral components from the sample diffusing into the salt bridge, which can result in cross contamination among samples.
\end{abstract}

Keywords Reference electrodes, nanoporous glass, salt bridges, charge screening

(Received June 26, 2019; Accepted August 22, 2019; Advance Publication Released Online by J-STAGE September 6, 2019)

\section{Introduction}

The measurement of stable and reproducible reference potentials is an area of interest for many but is not without its complications. ${ }^{1-14}$ Consistent and constant reference potentials are particularly difficult to measure in very dilute aqueous solutions, a problem of concern especially for accurate $\mathrm{pH}$ measurements of environmental importance. ${ }^{9,15-18}$ In many cases, salt bridges are used to provide for electrical contact between reference electrodes and samples. ${ }^{19,20}$ At the liquid junction formed between two mutually miscible electrolyte solutions, a junction potential develops that depends on the concentrations, mobilities, and charges of all ions involved. ${ }^{21}$ It is well known that electrolytes of salt bridges with matched cation and anion mobilities and a high concentration can be selected so as to minimize and dominate this liquid junction potential. ${ }^{22}$

To reduce the cross contamination of samples and the salt bridge electrolyte by convective mixing, porous glasses with pore diameters of $4-10 \mathrm{~nm}$ have been used to contain the salt bridge., ${ }^{4,23}$ Unfortunately, this can introduce complications due to electrostatic screening by electrical charges on the pore walls of these frits. ${ }^{23}$ In particular, sample-dependent phase boundary potentials were shown to develop at the interface of nanoporous glass frits with $4-6 \mathrm{~nm}$ pores due to the negatively charged

$\dagger$ To whom correspondence should be addressed.

E-mail: buhlmann@umn.edu surface of glass (e.g., sample cations freely enter the frit pores but anions are excluded) in all but very acidic solutions. ${ }^{23}$ Therefore, the use of reference electrodes with frits that have such small pores is not recommended when measuring in dilute solutions, where the Debye length of the solution is larger than the size of the frit pores (Fig. 1). ${ }^{23}$ A similar type of electrostatic screening has also been observed in electrically conducting nanoporous materials. ${ }^{24}$ Reference electrodes with $500-$ $1000 \mathrm{~nm}$ pores $^{4}$ did not exhibit charge screening in solutions with an ionic strength from $1 \times 10^{-1}$ to $1 \times 10^{-6} \mathrm{M}$ and provide for reference potentials that can be predicted very accurately after correction of the liquid junction potential as calculated, e.g., with the Henderson equation..$^{22,25-28}$ However, frits with $500-1000 \mathrm{~nm}$ pores allow for a flow rate of the bridge electrolyte into the sample that is often unacceptably large. ${ }^{4}$ Similarly, polymeric frits with 1 and $10 \mu \mathrm{m}$ pores were found to exhibit no charge screening but had flow rates that quickly contaminated samples and required frequent replenishing of bridge electrolyte. ${ }^{4}$ Reference electrodes comprising polymeric frit materials with much smaller pore sizes are feasible but at this point require custom synthesis and are not easy to functionalize with a hydrophilic surface that does not bind certain ions specifically. ${ }^{?}$

To this end, we tested in the work presented here commercially available porous glass frits with pore diameters of 1, 5, 20, 50, and $100 \mathrm{~nm}$. The frits were used to separate a $3.0 \mathrm{M} \mathrm{KCl}$ bridge electrolyte solution from different types of sample solutions. Because stirring of samples of low ionic strength has been shown recently to enhance the level of charge screening through 

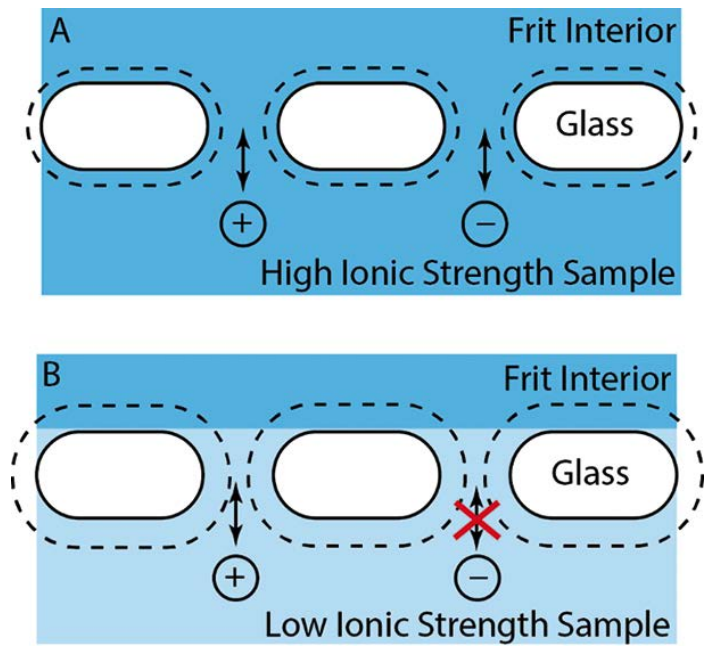

Fig. 1 Illustration of charge screening at the interface of a reference electrode frit and different samples. Dotted lines indicate Debye length. Panel A: Frit in contact with a sample of high ionic strength, where ions diffuse freely. Panel B: Frit in contact with a sample of low ionic strength, where negatively charged ions are screened by the negative surface charge of the glass frit.

the reduction of electrolyte strength that accompanies the convective penetration of sample into a surface layer of a few nanometers of the frit, ${ }^{29}$ potentials in this work were monitored in both stirred and unstirred solutions. To determine the suitability of these electrodes for measurements of environmental waters, potentials of electrodes equipped with glass junctions with each pore size were also measured in solutions of $\mathrm{pH} 1.5$ to 12.5 without background electrolyte, and, therefore, low ionic strength. Linear flow rates for each type of frit were determined and compared to the minimum flow rate required to avoid contamination to the reference electrode frits due to diffusion of sample components into the frit.

\section{Experimental}

\section{Materials}

Aqueous solutions were prepared using deionized and charcoal-treated water $(>18.2 \mathrm{M} \Omega \mathrm{cm}$ specific resistance) obtained with a Milli-Q PLUS reagent grade water system (Millipore, Bedford, MA). $\mathrm{AgCl}(98 \%), \mathrm{KCl}, \mathrm{Na}_{2} \mathrm{SO}_{4}, \mathrm{CaCl}_{2}$, $1.0 \mathrm{M} \mathrm{NaOH}$, and $1.0 \mathrm{M} \mathrm{HCl}$ were purchased from SigmaAldrich, Ag wires (0.5 mm diameter, $\geq 99.9 \%)$ from Alfa Aesar (Tewksbury, MA), and porous glass disks (15 mm diameter; $1.2 \mathrm{~mm}$ thick; $1.0 \pm 0.1,5.0 \pm 0.5,20 \pm 2,50 \pm 5$, and $100 \pm$ $10 \mathrm{~nm}$ diameter pores) from Boraglas (Stuttgart, Germany). All chemicals were used as received.

\section{Reference electrode fabrication}

Each porous glass disk was immersed in $3.0 \mathrm{M} \mathrm{KCl}$ for a least 3 days before being mounted onto a custom-made poly(chlorotrifluoroethylene) electrode body (Fig. S1, Supporting Information), sandwiching the frit between two Viton washers. This resulted in a circular area of $8.3 \mathrm{~mm}$ diameter of the frit exposed to the sample solutions. Electrode bodies were filled with $3.0 \mathrm{M} \mathrm{KCl}$ saturated with $\mathrm{AgCl}$, and $\mathrm{AgCl} / \mathrm{Ag}$ wires (prepared as reported previously) ${ }^{29}$ were inserted into this inner solution. The electrode bodies were not sealed, allowing for pressure equalization with the ambient air and, therefore, for flow of inner filling solution out of the electrodes through the porous glass.

\section{Potential measurements}

Potentials $(E)$ were measured at room temperature in unstirred or stirred solutions (as discussed in the Results and Discussion) with an EMF 16 potentiometer (Lawson Labs, Malvern, PA) controlled with EMF Suite 1.02 software (Fluorous Innovation, Arden Hill, MN). A Corning PC-420D stir plate was used with a $150 \mathrm{~mL}$ glass beaker $(55 \times 85 \mathrm{~cm})$ and a $1.0 \times 6.4 \mathrm{~mm}$ Tefloncoated cylindrical magnetic stir bar. The stir bar rotation rate was kept constant at 400 rotations per minute. Potentials were measured relative to a free-flowing double-junction reference electrode (DX200, Mettler Toledo, Switzerland) with $3.0 \mathrm{M}$ $\mathrm{KCl}$ bridge electrolyte and $\mathrm{AgCl}$-saturated $3.5 \mathrm{M} \mathrm{KCl}$ reference electrolyte. ${ }^{28}$ Activity coefficients were calculated using a twoparameter Debye-Hückel approximation, ${ }^{30}$ and potential measurements of aqueous electrolytes (excluding $\mathrm{pH}$ ) were corrected for liquid junction potentials using the Henderson equation. $^{21}$ The $\mathrm{pH}$ was monitored using a glass electrode from Hanna Instruments (Smithfield, RI) and adjusted by additions of $1.0 \mathrm{M} \mathrm{HCl}$ and $1.0 \mathrm{M} \mathrm{NaOH}$. $\mathrm{KCl}$ concentrations were adjusted by serial dilution of concentrated solutions. $\mathrm{Na}_{2} \mathrm{SO}_{4}$ and $\mathrm{CaCl}_{2}$ concentrations were adjusted by addition of concentrated stocks solutions to deionized and charcoal-treated water.

\section{Flow rate of salt bridge electrolyte}

Flow rates of the salt bridge solution through the frits into samples $(5,20,50$, and $100 \mathrm{~nm})$ were measured by storing the electrodes in a sealed container with $100 \%$ humidity. The inner compartments of the reference electrodes were filled with $3.0 \mathrm{M}$ $\mathrm{KCl}$ to a solution height of $100 \mathrm{~mm}$ versus the sample surface, and the solution height was monitored over a 30 day period (repeated three times).

\section{Resistance measurements}

Resistance was measured using a Solartron 1255B frequency response analyzer with an SI 1287 electrochemical interface (Farnborough, Hampshire, UK) controlled by ZPlot software (Scribner Associates, Southern Pines, NC). Measurements were performed at the open circuit potential with an AC amplitude of $100 \mathrm{mV}$ in $3.0 \mathrm{M} \mathrm{KCl}$. Data was collected using a Pt gauze $(50 \times 13 \mathrm{~mm})$ counter electrode and a $\mathrm{AgCl} / \mathrm{Ag}$ wire reference electrode. All data fits were performed using Mathematica 10.1 (Champaign, IL).

\section{Results and Discussion}

\section{Reference potentials in stirred and unstirred $\mathrm{KCl}$ electrolyte solutions}

Prior to potential measurements, the electrical resistances of reference electrodes with $1,5,20,50$, and $100 \mathrm{~nm}$ pores were determined. The thus determined electrical resistances are consistent with those previously reported for Vycor $(69 \pm 17 \Omega)$ and CoralPor $(139 \pm 53 \Omega)$ frits, which confirms that each frit was filled to a substantial extent with the $3.0 \mathrm{M} \mathrm{KCl}$ inner filling solution (Table 1). ${ }^{4}$ To simulate typical applications, the half-cell potentials of reference electrodes with glass junctions with $5,20,50$, or $100 \mathrm{~nm}$ diameter pores (from here on referred to as half-cell potentials of reference electrodes with porous junctions) were measured with respect to a conventional freeflowing double-junction reference electrode in vigorously stirred (400 rotations per minute) $\mathrm{KCl}$ solutions (Fig. 2). The half-cell potentials of reference electrodes with porous junctions with 
Table 1 Volumetric flow rate, resistance, and linear flow rates of reference electrodes with 1, 5, 20, 50, and $100 \mathrm{~nm}$ pore glass frits

\begin{tabular}{lccccc}
\hline & $1 \mathrm{~nm}$ & $5 \mathrm{~nm}$ & $20 \mathrm{~nm}$ & $50 \mathrm{~nm}$ & $100 \mathrm{~nm}$ \\
\hline Volumetric flow rate $(\mu \mathrm{L} / \mathrm{h})$ & $<0.035^{\mathrm{a}}$ & $0.035 \pm 0.027$ & $0.67 \pm 0.07$ & $3.0 \pm 0.6$ & $14.0 \pm 0.5$ \\
Resistance $(\Omega$, filled with 3 M KCl) & $8000 \pm 1000$ & $240 \pm 20$ & $130 \pm 10$ & $130 \pm 10$ & $130 \pm 10$ \\
Linear flow rate $(\mathrm{mm} / \mathrm{h})$ & $<8.9 \times 10^{-4 \mathrm{a}}$ & $8.9 \times 10^{-4}$ & $1.7 \times 10^{-2}$ & $7.6 \times 10^{-2}$ & $3.6 \times 10^{-1}$ \\
\hline
\end{tabular}

a. Not determined experimentally.

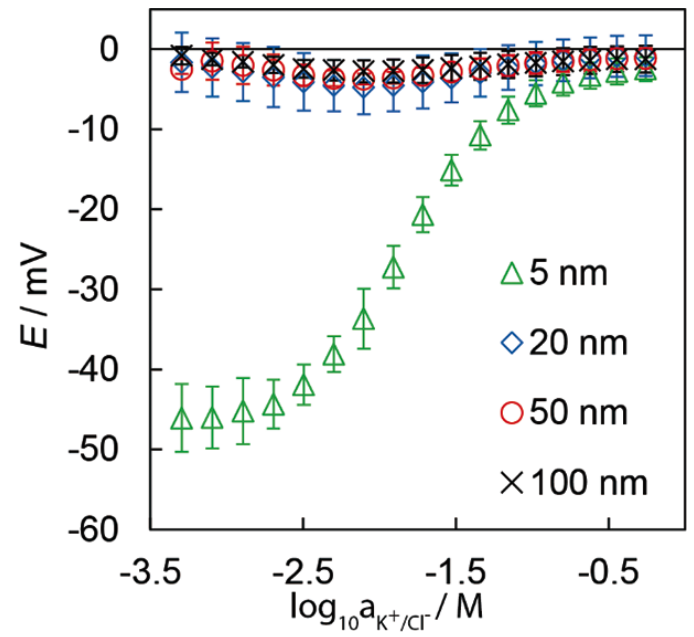

Fig. 2 Potentials of reference electrodes as a function of $\mathrm{K}^{+} / \mathrm{Cl}^{-}$ activity of a $\mathrm{KCl}$ solution under stirred conditions. $E$ was measured relative to a free-flowing double-junction reference electrode. All $E$ values are corrected for liquid junction potentials at the free-flowing double junction. Error bars are $95 \%$ confidence intervals for the average of three separate experiments.

20,50 , and $100 \mathrm{~nm}$ pores were statistically equivalent over the entire concentration range studied $\left(1.0 \mathrm{M}-3.3 \times 10^{-4} \mathrm{M} \mathrm{KCl}\right)$, while the half-cell potentials of the electrodes with junctions with $5 \mathrm{~nm}$ pores deviated significantly at intermediate and lower ionic strengths, indicating charge screening due to repulsion of sample anions by the negative charges on the glass surfaces. An independence of the half-cell potential of reference electrodes with porous junctions on the ionic strength has previously also been reported for reference electrodes with Electro-porous KT glass frits (500 - $1000 \mathrm{~nm}$ pores), which is consistent with their large pore size. It is worth noting that a substantial part of the experimentally observed electrode-to-electrode potential deviation for junctions with a given pore size (as indicated by the error bars in Fig. 2) can be explained by the variability of the $\mathrm{AgCl}$-coated $\mathrm{Ag}$ wires used as the inner reference electrodes. In our experiments, the standard deviation of the EMF of $\mathrm{AgCl}$ coated $\mathrm{Ag}$ wires in $100 \mathrm{mM} \mathrm{KCl}$ versus a free-flowing reference electrode was measured to be $\pm 2.8 \mathrm{mV} \quad(n=3)$. Similar variabilities have been reported in the literature for $\mathrm{AgCl}$-coated $\mathrm{Ag}$ wires and have been attributed, among other factors, to mechanical strains in the silver wire. ${ }^{31}$

For comparison to previously reported results, half-cell potentials of reference electrodes with porous junctions were also measured in stirred solutions of $\mathrm{Na}_{2} \mathrm{SO}_{4}$ and $\mathrm{CaCl}_{2}$ (Figs. S2 and $\mathrm{S} 3$, Supporting Information). ${ }^{4}$ As for $\mathrm{KCl}$ sample solutions too, measurements of potentials in $\mathrm{Na}_{2} \mathrm{SO}_{4}$ and $\mathrm{CaCl}_{2}$ solutions indicate that half-cell potentials of reference electrodes using porous glass junctions with 20,50 , and $100 \mathrm{~nm}$ pores do not suffer from charge screening at the sample interface of the frit.
To assess the effect of sample stirring, the half-cell potentials of reference electrodes with glass frit junctions with pore diameters of $1,5,20,50$, or $100 \mathrm{~nm}$ were measured in $\mathrm{KCl}$ solutions both under stirred (400 rotations per minute) and unstirred conditions (see Figs. S4, S5, and S6, Supporting Information). At high electrolyte strengths $(>0.1 \mathrm{M} \mathrm{KCl})$, the half-cell potential of each electrode did not depend on whether the solutions were stirred or not. However, as the concentration of $\mathrm{KCl}$ was reduced $(<0.1 \mathrm{M} \mathrm{KCl})$, the potentials of reference electrodes with a 1 or $5 \mathrm{~nm}$ pore diameter frit deviated for samples of low ionic strength significantly from those for electrodes with 20,50 , or $100 \mathrm{~nm}$ pore frits. This finding is consistent with observations reported previously for glass frits commercially available under the tradenames Vycor $(4-6 \mathrm{~nm}$ pores) and CoralPor (4-10 nm pores). ${ }^{4}$ In addition, reference electrodes with a 1 or $5 \mathrm{~nm}$ pore diameter frit showed a response to solution stirring, which is consistent with an increase in charge screening as the result of the penetration of the sample a few nanometers into the frit, resulting in the dilution of the bridge electrolyte concentration with sample and, thereby, an increase in the local Debye length. ${ }^{29}$

Reference potentials in stirred and unstirred solutions of $\mathrm{pH} 1.5$ to 12.5

Half-cell potentials of reference electrodes with a Vycor frit ( $4-6 \mathrm{~nm}$ pores) have been reported to vary $\approx 40 \mathrm{mV}$ from $\mathrm{pH}=2$ to $\mathrm{pH}=12$ in a $0.01 \mathrm{M} \mathrm{KCl}$ background. ${ }^{4}$ Here we determined the half-cell potentials of reference electrodes with glass junctions with 5, 20, 50 and $100 \mathrm{~nm}$ pore diameters from $\mathrm{pH} 1.5$ to 12.5 in unstirred and stirred solutions containing no background electrolyte (Figs. 3, 4, 5, and 6; see also Figs. S7 and S8, Supporting Information). This type of experiment was performed to simulate the $\mathrm{pH}$ measurement of rainwater, ${ }^{27,32-34}$ where no background electrolyte is present, and Debye lengths are large.

As Fig. 3 shows, the half-cell potentials of reference electrodes with glass junctions with $5 \mathrm{~nm}$ pores did not deviate significantly from that of reference electrodes with a free-flowing liquid junction in unstirred solutions until a $\mathrm{pH}$ greater than 9 was reached. Note that potentials in Fig. 3 were not corrected for the liquid junction potential at the free-flowing double junction electrode with respect to which the potential were determined. Therefore, the absence of deviations in the half-cell potential indicates that the half-cell potential of the free-flowing liquid junction, with contributions from the liquid junction potential at the interface of the $3 \mathrm{M} \mathrm{KCl}$ bridge electrolyte with the sample, is the same as that of the porous frit reference electrode. In contrast to the results for frits with $5 \mathrm{~nm}$ pores in unstirred solutions, in stirred solutions, these electrodes show significant deviations in half-cell potentials from $\mathrm{pH} 1.5$ to 12.5 of up to $\approx 40 \mathrm{mV}$ (Fig. 3). This large deviation is consistent with what has been reported for Vycor frits $(4-6 \mathrm{~nm}$ pores $){ }^{4}$

Electrodes with $20 \mathrm{~nm}$ pore frits (Fig. 4) and, to a lesser extent, electrodes with $50 \mathrm{~nm}$ pore frits (Fig. 5) showed slight deviations from ideal liquid junction behavior at $\mathrm{pH}$ values of 


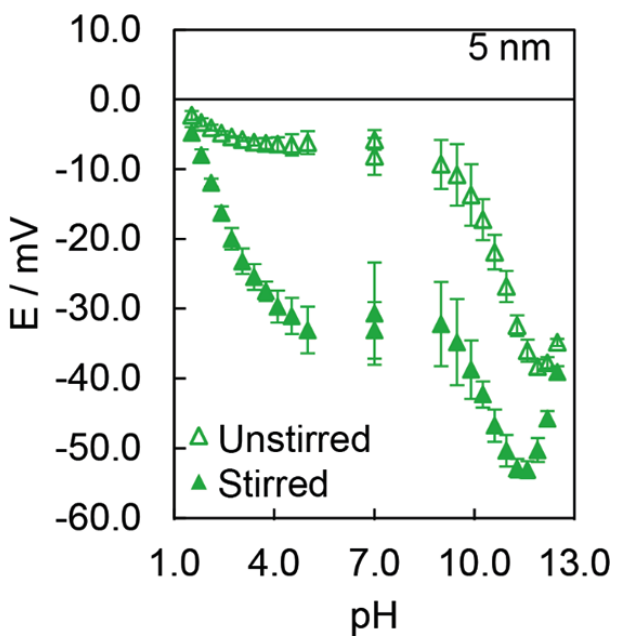

Fig. 3 Potentials, $E$, of reference electrodes with $5 \mathrm{~nm}$ pores as a function of $\mathrm{pH}$ in unstirred and stirred solutions, measured relative to a free-flowing double-junction reference electrode. Data is not corrected for liquid junction potentials. Error bars are 95\% confidence intervals for the average of three separate experiments.

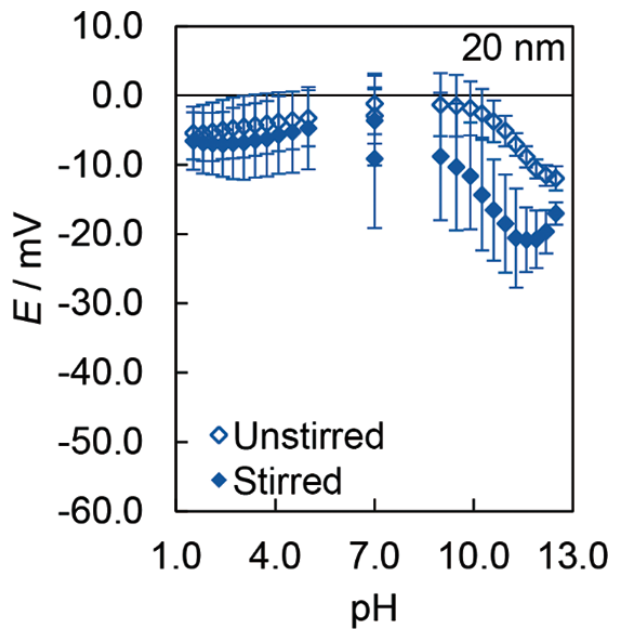

Fig. 4 Potentials, $E$, of reference electrodes with $20 \mathrm{~nm}$ pores as a function of $\mathrm{pH}$ in unstirred and stirred solutions, measured relative to a free-flowing double-junction reference electrode. Data is not corrected for liquid junction potentials. Error bars are 95\% confidence intervals for the average of three separate experiments.

10 to 12 , as evident from the difference in $E$ in the unstirred and stirred cases. This indicates that charge screening occurs in this case for the 20 and $50 \mathrm{~nm}$ pores too, unlike in the case of the $\mathrm{KCl}, \mathrm{Na}_{2} \mathrm{SO}_{4}$ and $\mathrm{CaCl}_{2}$ experiments shown in Figs. 1, S2, and S3. In addition, potential deviations increased in stirred solutions, which is consistent with an increase in charge screening as the result of the penetration of the sample solution into the frits. In contrast, the half-cell potentials of electrodes with glass junctions with $100 \mathrm{~nm}$ pores did not deviate significantly from those for reference electrodes with a freeflowing liquid junction, nor did their half-cell potential depend on the solution being stirred or not (Fig. 6). This shows that reference electrodes with pore diameters $\geq 100 \mathrm{~nm}$ can be used without charge screening contributing to the measured half-cell potential. $^{21}$

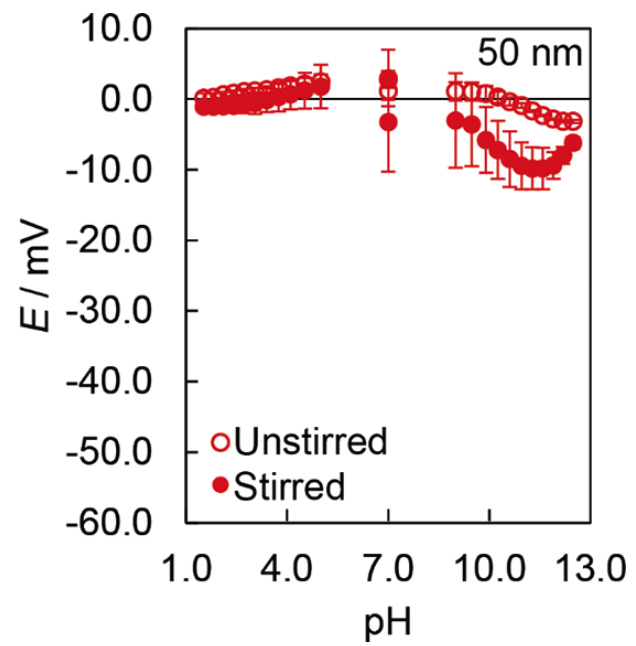

Fig. 5 Potentials, $E$, of reference electrodes with $50 \mathrm{~nm}$ pores as a function of $\mathrm{pH}$ in unstirred and stirred solutions, measured relative to a free-flowing double-junction reference electrode. Data is not corrected for liquid junction potentials. Error bars are $95 \%$ confidence intervals for the average of three separate experiments.

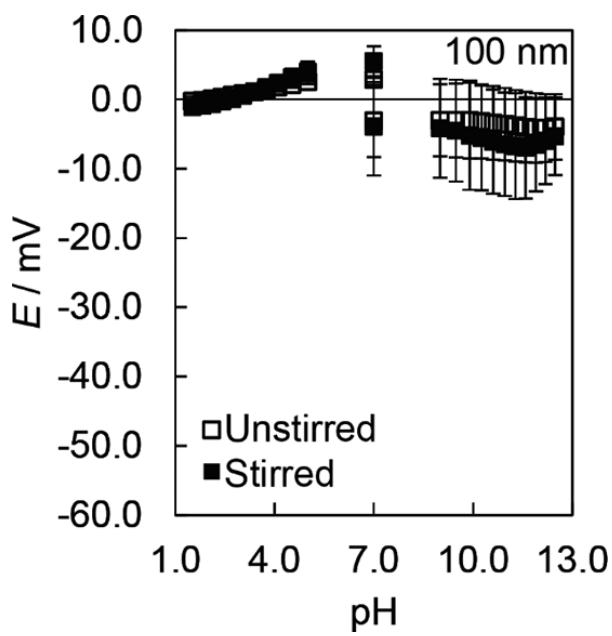

Fig. 6 Potentials, $E$, of reference electrodes with $100 \mathrm{~nm}$ pores as a function of $\mathrm{pH}$ in unstirred and stirred solutions, measured relative to a free-flowing double-junction reference electrode. Data is not corrected for liquid junction potentials. Error bars are $95 \%$ confidence intervals for the average of three separate experiments.

\section{Flow rate of the bridge electrolyte}

Previously, we reported that the flow rate of reference electrodes is an important factor in determining the level of contamination that may occur from diffusion of small sample ions into the porous frit, with small ions such as $\mathrm{K}^{+}, \mathrm{Cl}^{-}$, and $\mathrm{Fe}^{3+}$ diffusing a few millimeters over $1 \mathrm{~h} .{ }^{29}$ Here we determined the volumetric flow rates of reference electrodes with nanoporous glass frits using a setup in which the bridge electrolyte level in the reference electrode was $100 \mathrm{~mm}$ higher than in the sample, producing a pressure of $9.8 \times 10^{-3}$ bar. This resulted in volumetric flow rates for $5,20,50$, and $100 \mathrm{~nm}$ pores in the range from 0.0035 to $14 \mu \mathrm{L} / \mathrm{h}$ (see Table 1 ). These values were converted to linear flow rates with which solution passes through the nanoporous frits by dividing the volumetric flow rates by the fraction of the frit cross section not occupied by glass 
$\left(3.9 \times 10^{-5} \mathrm{~m}^{2}\right)$. This resulted in flow rates between $8.9 \times$ $10^{-4} \mathrm{~mm} / \mathrm{h}$ for the smallest and $3.6 \times 10^{-1} \mathrm{~mm} / \mathrm{h}$ for the largest pore frits. Flow rates for the $1 \mathrm{~nm}$ pore frits could not be measured with this method because of the extremely small flow rate. The comparison of these linear flow rates with the typical distance small ions diffuse in $1 \mathrm{~h}$ shows that diffusion dominates the transport of ions for all pore diameters studied. Therefore, the solution within the porous frits will be contaminated by sample solutions over the timescale of typical experiments. While the glass frits with pore diameters of 50 and $100 \mathrm{~nm}$ show no charge screening in solutions of varying $\mathrm{pH}$ and ionic strength, contamination of the bridge electrolyte may alter reference potentials over the time course of measurements and contribute to cross contamination between different samples. This linear flow rate could be increased by pressurizing the inner filling solution, but that would lead to increased volumetric flow rates, which is not desirable.

\section{Conclusions}

The half-cell potentials of reference electrodes comprising porous glass frits with pore diameters between 1 and $100 \mathrm{~nm}$ were measured in solutions of varying electrolyte concentration and $\mathrm{pH}$. On one hand, half-cell potentials of electrodes with glass junctions with pore diameters of 1, 5, 20, and $50 \mathrm{~nm}$ were found to depend both on the sample and stirring conditions. These changes in half-cell potential result from charge screening of ions at the interface of the porous frit and the sample. This makes these pore sizes undesirable for reference electrode use in samples of intermediate or low ionic strength. On the other hand, electrodes comprising frits with pore diameters of $100 \mathrm{~nm}$ were found to provide half-cell potentials that only depend on the liquid junction potentials as it can be predicted with the Henderson equation, not affected by charge screening. However, while the half-cell potentials of the reference electrodes with $100 \mathrm{~nm}$ pore frits did not vary with the ionic strength, the flow rates of their salt bridges were found to be too low to limit diffusion of sample components into the frits when the only force driving convective flow through the frit was the pressure resulting from a bridge electrolyte level $100 \mathrm{~mm}$ above the sample surface. This can cause contamination of the frit and carry-over of contaminants into subsequent samples.

Having tested 1, 5, 20, 50, and $100 \mathrm{~nm}$ glass frits, we can recommend use of the $100 \mathrm{~nm}$ glass frits for applications that involve samples of low ionic strength. However, when cross contamination of samples and bridge electrolyte is a concern, liquid junctions characterized by a small volumetric but a large linear flow rate of the bridge electrolyte into the sample are preferable. In such cases, other junction types, such as capillary junctions, appear superior to junctions with porous frits.

\section{Acknowledgements}

E. L. A. thankfully acknowledges a Lester C. and Joan M. Krogh Endowed Fellowship, an ACS Division of Analytical Chemistry and Eastman Summer Fellowship, a Richard D. Amelar and Arthur S. Lodge Fellowship, and a Dissertation Fellowship from the Graduate School, University of Minnesota. We thank Dr. Matthäus Speck for referring us to a commercial source of nanoporous glass frits with various pore diameters.

\section{Supporting Information}

Figures that show a schematic of the electrode body. Potentials of reference electrodes in stirred solutions of $\mathrm{Na}_{2} \mathrm{SO}_{4}$ and $\mathrm{CaCl}_{2}$, and in stirred and unstirred solutions of $\mathrm{KCl}$. Alternative representation of data from Figs. 3, 4, 5, and 6, facilitating comparison of data for frits with different pore sizes, for either stirred or unstirred solutions. This material is available free of charge on the Web at http://www.jsac.or.jp/analsci/.

\section{References}

1. G. Inzelt, A. Lewenstam, and F. Scholz, "Handbook of Reference Electrodes", 2013, Springer, Heidelberg, Germany.

2. A. Kisiel, H. Marcisz, A. Michalska, and K. Maksymiuk, Analyst, 2005, 130, 1655.

3. Y. Kudo, M. Shibata, S. Nomura, and N. Ogawa, Anal. Sci., 2017, 33, 739.

4. M. P. Mousavi, S. A. Saba, E. L. Anderson, M. A. Hillmyer, and P. Bühlmann, Anal. Chem., 2016, 88, 8706.

5. X. U. Zou and P. Bühlmann, Anal. Chem., 2013, 85, 3817.

6. T. Kakiuchi and M. Yamamoto, Bunseki Kagaku, 2016, 65, 181.

7. E. L. Anderson, S. A. Saba, D. J. Loomis, P. Bühlmann, and M. A. Hillmyer, ACS Appl. Nano Mater., 2017, 1, 139.

8. E. Bakker, Electroanalysis, 1999, 11, 788.

9. P. Spitzer and B. Werner, Anal. Bioanal. Chem., 2002, 374, 787.

10. T. Kakiuchi, T. Yoshimatsu, and N. Nishi, Anal. Chem., 2007, 79, 7187.

11. J. Hu, A. Stein, and P. Bühlmann, TrAC, Trends Anal. Chem., 2016, 76, 102.

12. T. Guinovart, G. A. Crespo, F. X. Rius, and F. J. Andrade, Anal. Chim. Acta, 2014, 821, 72.

13. E. Lindner, M. Guzinski, T. A. Khan, and B. D. Pendley, ACS Sens., 2019, 4, 549.

14. F. Gao, S. Broadley, T.-Y. Chen, P. M. Payne, and H. Silverman, ECS Trans., 2006, $1,1$.

15. W. Davison and C. Woof, Anal. Chem., 1985, 57, 2567.

16. R. C. Metcalf, Analyst, 1987, 112, 1573.

17. D. Midgley, Atmos. Environ., 1987, 21, 173.

18. W. Davison and T. R. Harbinson, Analyst, 1988, 113, 709.

19. G. A. Perley and C. W. Davis, J. Phys. Chem., 1915, 20, 151.

20. H. A. Fales and W. A. Mudge, J. Am. Chem. Soc., 1920, 42, 2434.

21. A. Bard and L. Faulkner, "Electrochemical Methods: Fundamentals and Applications", 2001, John Wiley and Sons, Hoboken, New Jersey.

22. W. E. Morf, "The Principles of Ion-selective Electrodes and of Membrane Transport", 1981, Elsevier, New York.

23. M. P. Mousavi and P. Bühlmann, Anal. Chem., 2013, 85, 8895.

24. Y. Kitazumi, O. Shirai, M. Yamamoto, and K. Kano, Electrochim. Acta, 2013, 112, 171.

25. W. E. Morf, Anal. Chem., 1977, 49, 810.

26. H. W. Harper, J. Phys. Chem., 1985, 89, 1659.

27. W. Davison, A. K. Covington, and P. D. Whalley, Anal. Chim. Acta, 1989, 223, 441.

28. R. E. Dohner, D. Wegmann, W. E. Morf, and W. Simon, Anal. Chem., 1986, 58, 2585.

29. E. L. Anderson, T. P. Lodge, T. Gopinath, G. Veglia, and P. Bühlmann, Anal. Chem., 2019, 91, 7698.

30. P. C. Meier, Anal. Chim. Acta, 1982, 136, 363.

31. D. T. Saywer, A. Sobkowiak, and J. L. Roberts, "Electrochemistry for Chemists", 1995, Wiley, New York, 188

32. R. Kadis and I. Leito, Anal. Chim. Acta, 2010, 664, 129.

33. A. K. Covington, P. D. Whalley, and W. Davison, Pure Appl. Chem., 1985, 57, 877.

34. T. Ozeki, Y. Tsubosaka, S. Nakayama, N. Ogawa, and T. Kimoto, Anal. Sci., 1998, 14, 749. 